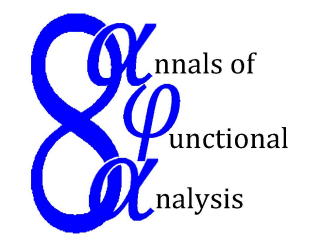

Ann. Funct. Anal. 6 (2015), no. 3, 155-165

http://doi.org/10.15352/afa/06-3-13

ISSN: 2008-8752 (electronic)

http://projecteuclid.org/afa

\title{
ON THE HALPERN ITERATION IN CAT(0) SPACES
}

\author{
HADI KHATIBZADEH AND SAJAD RANJBAR*
}

Communicated by M. A. Japon Pineda

\begin{abstract}
In this paper, strong convergence of Halpern iteration is shown for a quasi-strongly nonexpansive sequence of multivalued mappings in complete CAT(0) spaces.
\end{abstract}

\section{INTRODUCTION AND PRELIMINARIES}

Let $C$ be a nonempty subset of a metric space $(X, d)$. We shall write the family of nonempty closed bounded subsets of $C$ by $C B(C)$ and the family of nonempty compact subsets of $C$ by $K(C)$. Let $H(.,$.$) be the Hausdorff metric on C B(C)$, i.e.,

$$
H(A, B)=\max \left\{\sup _{a \in A} \operatorname{dist}(a, B), \sup _{b \in B} \operatorname{dist}(A, b)\right\}, \quad A, B \in C B(X) .
$$

A set-valued mapping $T: C \rightarrow C B(C)$ is said to be a contraction if there exists a constant $k \in(0,1)$ such that $H(T x, T y) \leq k d(x, y)$ and if $k=1$, then $T$ is called nonexpansive. A point $x \in C$ is called a fixed point of $T$ if $x \in T x$. We write $F(T):=\{x \in C: x \in T x\}$. The mapping $T: C \rightarrow C B(X)$ is called quasi-strongly nonexpansive if $T$ is nonexpansive with $F(T) \neq \emptyset$ and

$$
d\left(x_{n}, v_{n}\right) \rightarrow 0, \quad \forall v_{n} \in T x_{n},
$$

whenever $\left\{x_{n}\right\}$ is a bounded sequence in $C$ such that $d\left(x_{n}, p\right)-H\left(T x_{n}, T p\right) \rightarrow 0$ for some $p \in F(T)$. Also, a sequence of nonexpansive mappings $\left\{T_{n}\right\}$ from $C$ into $C B(X)$ is called a quasi-strongly nonexpansive sequence if $\bigcap_{n} F\left(T_{n}\right) \neq \emptyset$ and

$$
d\left(x_{n}, u_{n}\right) \rightarrow 0, \quad \forall u_{n} \in T_{n} x_{n},
$$

Date: Received: Nov. 12, 2014; Accepted: Jan. 20, 2015.

* Corresponding author.

2010 Mathematics Subject Classification. Primary 47H09; Secondary 47H10.

Key words and phrases. Halpern iteration, CAT(0) space, fixed point, quasi-strongly nonexpansive mapping. 
whenever $\left\{x_{n}\right\}$ is a bounded sequence in $C$ such that $d\left(x_{n}, p\right)-H\left(T_{n} x_{n}, T_{n} p\right) \rightarrow 0$ for some $p \in \bigcap_{n} F\left(T_{n}\right)$.

Example 1.1. Let $X=[0, \infty) \times[0, \infty)$ with the metric

$$
d\left(\left(x_{1}, x_{2}\right),\left(y_{1}, y_{2}\right)\right)=\left\{\begin{array}{ll}
x_{1}+y_{1}+\left|x_{2}-y_{2}\right|, & x_{2} \neq y_{2}, \\
\left|x_{1}-y_{1}\right|, & x_{2}=y_{2} .
\end{array} .\right.
$$

Then $(X, d)$ is a $\mathbb{R}$-tree (see [2], p. 167 and 168). Define $T: X \rightarrow 2^{X}$ with $T\left(\left(x_{1}, x_{2}\right)\right)=\left[\frac{x_{1}}{3}, \frac{x_{1}}{2}\right] \times\left[\frac{x_{2}}{3}, \frac{x_{2}}{2}\right]$. Then the mapping $T$ is a quasi-strongly nonexpansive mapping. Also, the sequence $\left(T_{n}: X \rightarrow 2^{X}\right)_{n=1}^{\infty}$ with

$$
\left\{\begin{array}{l}
T_{1}\left(\left(x_{1}, x_{2}\right)\right)=\{(0,0)\}, \quad\left(\left(x_{1}, x_{2}\right) \in X\right), \\
T_{n}\left(\left(x_{1}, x_{2}\right)\right)=\left[\frac{x_{1}}{n+1}, \frac{x_{1}}{n}\right] \times\left[\frac{x_{2}}{n+1}, \frac{x_{2}}{n}\right], \quad n \geq 2, \quad\left(\left(x_{1}, x_{2}\right) \in X\right),
\end{array}\right.
$$

is a quasi-strongly nonexpansive sequence.

A geodesic space $(X, d)$ is called a $\mathrm{CAT}(0)$ space if satisfies the following inequality:

$C N$ - inequality: for every $y_{1}, y_{2}, x \in X$ and all $y_{0} \in X$ such that $d\left(y_{0}, y_{1}\right)=d\left(y_{0}, y_{2}\right)=\frac{1}{2} d\left(y_{1}, y_{2}\right)$, one has

$$
d^{2}\left(x, y_{0}\right) \leq \frac{1}{2} d^{2}\left(x, y_{1}\right)+\frac{1}{2} d^{2}\left(x, y_{2}\right)-\frac{1}{4} d^{2}\left(y_{1}, y_{2}\right)
$$

A complete CAT(0) space is called a Hadamard space. It is known that a $\operatorname{CAT}(0)$ space is an uniquely geodesic space. For all $x$ and $y$ belong to a $\operatorname{CAT}(0)$ space $X$, we write $(1-t) x \oplus t y$ for the unique point $z$ in the geodesic segment joining from $x$ to $y$ such that $d(z, x)=t d(x, y)$ and $d(z, y)=(1-t) d(x, y)$. Set $[x, y]=\{(1-t) x \oplus t y: t \in[0,1]\}$, a subset $C$ of $X$ is called convex if $[x, y] \subseteq C$ for all $x, y \in C$. For other equivalent definitions and basic properties, we refer the reader to the standard texts such as $[2,3,7,9]$.

Fixed-point theory in CAT(0) spaces was first studied by Kirk (see [11, 10]). He showed that every nonexpansive (single-valued) mapping defined on a bounded, closed and convex subset of a complete CAT(0) space always has a fixed point. Since then, the fixed-point theory for single-valued and multivalued mappings in CAT(0) spaces has been rapidly developed, and many papers have appeared. It is worth mentioning that fixed-point theorems in CAT(0) spaces (specially in $\mathbb{R}$-trees) can be applied to graph theory, biology, and computer science.

Halpern in [8] proved the strong convergence of the iteration

$$
x_{n+1}=\alpha_{n} u+\left(1-\alpha_{n}\right) T x_{n},
$$

under the certain condition on the control sequence $\alpha_{n}$ of positive numbers, where $T$ is a single-valued nonexpansive self-mapping on a closed and convex subset $C$ of a Hilbert space $H$ and $u, x_{1} \in C$. Also, he showed that the assumptions $C 1: \lim _{n \rightarrow \infty} \alpha_{n}=0$, $C 2: \sum_{n=1}^{\infty} \alpha_{n}=\infty$, are necessary for the convergence of the iteration (1.1) to a fixed point of $T$. He also proposed the following open problem: 
Are the conditions (C1) and (C2) sufficient to convergence of the sequence generated by (1.1) to a fixed point of $\mathrm{T}$ ?

Many mathematicians have investigated this question (see $[4,12,14,17,18]$ and references therein). The Halpern's iteration in a CAT(0) space $X$ is defined as follows,

$$
x_{n+1}=\alpha_{n} u \oplus\left(1-\alpha_{n}\right) T x_{n},
$$

where $T$ is a single-valued nonexpansive selfmapping on a closed and convex subset $C$ of $X, u, x_{1} \in C$ and $\left\{\alpha_{n}\right\}$ is a positive real sequence. Saejung [15] showed the strong convergence of the sequence $\left\{x_{n}\right\}$ given by (1.2) to a fixed point of the mapping $T$, under the conditions $C 1, C 2$ and $C 3: \sum_{n=1}^{\infty}\left|\alpha_{n+1}-\alpha_{n}\right|<\infty$ or $\lim _{n \rightarrow \infty} \frac{\alpha_{n}}{\alpha_{n+1}}=1$. Also, Saejung in [14] answered the Halpern open problem for the strongly nonexpensive mappings in certain Banach spaces. Dhompongsa and etal [5] extended the results of Saejung [15] to a sequence of set-valued nonexpansive mappings. In this paper, it is shown that $C 1$ and $C 2$ are sufficient for strong convergence of the Halpern iteration for a quasi-strongly nonexpansive sequence of set-valued mappings in Hadamard spaces. Our results extend the results of Saejung [14] and improve the results of Dhompongsa and etal [5].

This paper is organized as follows:

In Section 2, we prove some technical lammas that we need in the sequel. Section 3 is devoted to the main result of the paper. In this section, we prove the strong convergence of the Halpern iteration for a quasi-strongly nonexpansive sequence of set-valued mappings in Hadamard spaces. In Section 4, the result of Theorem 3.7 of [5] is proved without using of Banach limit.

\section{Some Lemmas}

The following technical lemma is well-known in CAT(0) spaces.

Lemma 2.1. [6] Let $(X, d)$ be a $C A T(0)$ space. Then, for all $x, y, z, w \in X$ and all $t \in[0,1]:$

(1) $\quad d^{2}(t x \oplus(1-t) y, z) \leq t d^{2}(x, z)+(1-t) d^{2}(y, z)-t(1-t) d^{2}(x, y)$,

(2) $d(t x \oplus(1-t) y, z) \leq t d(x, z)+(1-t) d(y, z)$,

In addition, by using (1), we have

$$
d(t x \oplus(1-t) y, t z \oplus(1-t) w) \leq t d(x, z)+(1-t) d(y, w) .
$$

In the following, we prove some lemmas that we need in the sequel.

Notation: Let $(X, d)$ be a $\operatorname{CAT}(0)$ space and $a, b, c, d \in X$. To simplify the calculations, we set $\langle a b, c d\rangle=\frac{1}{2}\left(d^{2}(a, d)+d^{2}(b, c)-d^{2}(a, c)-d^{2}(b, d)\right)$.

The following lemma is easy to verify.

Lemma 2.2. Let $(X, d)$ be a $C A T(0)$ space and $a, b, c, d, e \in X$, then

(i) $\langle a b, a b\rangle=d^{2}(a, b)$,

(ii) $\langle a b, c d\rangle=-\langle a b, d c\rangle$,

$(i i i)\langle a b, c d\rangle=\langle a e, c d\rangle\rangle+\langle e b, c d\rangle$. 
Lemma 2.3. Let $(X, d)$ be a $C A T(0)$ space and $a, b, c \in X$. Then for each $\lambda \in[0,1]$,

$$
d^{2}(\lambda a \oplus(1-\lambda) b, c) \leq \lambda^{2} d^{2}(a, c)+(1-\lambda)^{2} d^{2}(b, c)+2 \lambda(1-\lambda)\langle a c, b c\rangle .
$$

Proof. By Lemma 2.1, we get

$$
\begin{aligned}
d^{2}(\lambda a \oplus(1-\lambda) b, c) \leq & \lambda d^{2}(a, c)+(1-\lambda) d^{2}(b, c)-\lambda(1-\lambda) d^{2}(a, b) \\
= & \lambda^{2} d^{2}(a, c)+(1-\lambda)^{2} d^{2}(b, c)+\lambda(1-\lambda)\left(d^{2}(a, c)\right. \\
& \left.+d^{2}(b, c)-d^{2}(a, b)\right) \\
= & \lambda^{2} d^{2}(a, c)+(1-\lambda)^{2} d^{2}(b, c)+2 \lambda(1-\lambda)\langle a c, b c\rangle .
\end{aligned}
$$

If $C$ is a closed convex subset of a complete $\mathrm{CAT}(0)$ space $X, T: C \longrightarrow C B(X)$ is a nonexpansive mapping and $u \in C$, then for any $t \in(0,1)$, the mapping $S_{t}: C \rightarrow C B(X)$ by $S_{t}(x)=t u \oplus(1-t) T x$ is a contraction. Banach contraction principle has been extended to a set-valued contraction by Nadler [13]. Thus, for any $t \in(0,1)$ there exists a point $z_{t} \in C$ such that

$$
z_{t} \in S_{t} z_{t}=t u \oplus(1-t) T z_{t} .
$$

Notice that if $F(T) \neq \emptyset$ and $T(p)=\{p\}$ for all $p \in F(T)$, then for each $t \in(0,1)$ and $p \in F(T)$, we have $d\left(z_{t}, p\right) \leq d(u, p)$. Hence, $\left\{z_{t}\right\}$ is bounded. Therefore, we have the following Lemma.

Lemma 2.4. [5] Let $C$ be a closed convex subset of a complete CAT(0) space $X, T: C \longrightarrow K(X)$ be a nonexpansive non-self mapping with a fixed point such that $T(p)=\{p\}$ for all $p \in F(T)$, and $u \in C$. For each $t \in(0,1)$, set $z_{t}=t u \oplus(1-t) T z_{t}$. Then $z_{t}$ converges as $t \rightarrow 0$ to the unique fixed point of $T$, which is the nearest point to $u$.

Lemma 2.5. Let $C$ be a closed and convex subset of a complete $C A T(0)$ space $X$ and $T: C \longrightarrow K(X)$ be a nonexpansive non-self mapping with a fixed point such that $T(p)=\{p\}$ for all $p \in F(T)$. If $\left\{x_{n}\right\}$ is a bounded sequence in $C$ such that the sequence $\left\{d\left(x_{n}, v_{n}\right)\right\}$ converges to zero for all $v_{n} \in T x_{n}$, then for all $v_{n} \in T x_{n}$, we have

$$
\limsup _{n}\left\langle u p, v_{n} p\right\rangle \leq \limsup _{n}\left\langle u p, x_{n} p\right\rangle \leq 0
$$

where $u \in C$ and $p$ is the nearest point of $F(T)$ to $u$.

Proof. For each $t \in(0,1)$, there exists a point $z_{t} \in C$ such that $z_{t} \in t u \oplus(1-t) T\left(z_{t}\right)$. Let $y_{t} \in T\left(z_{t}\right)$, such that $z_{t}=t u \oplus(1-t) y_{t}$. By Lemma 2.4, as $t \rightarrow 0,\left\{z_{t}\right\}$ converges strongly to the unique fixed point $p$ of $T$, which is the nearest point of $F(T)$ to $u$. Moreover, for each $n$ and $t$, there exists $v_{n, t} \in T x_{n}$ such that $d\left(y_{t}, v_{n, t}\right)=\operatorname{dist}\left(y_{t}, T x_{n}\right)$. The sequence $\left\{v_{n, t}\right\}$ is bounded 
by $d\left(v_{n, t}, p\right)=\operatorname{dist}\left(v_{n, t}, T p\right) \leq H\left(T x_{n}, T p\right) \leq d\left(x_{n}, p\right)$. By Lemmas 2.2 and 2.3, for each $t \in(0,1)$ and all $n \in \mathbb{N}$, we have

$$
\begin{aligned}
d^{2}\left(z_{t}, x_{n}\right)= & d^{2}\left(t u \oplus(1-t) y_{t}, x_{n}\right) \\
\leq & t^{2} d^{2}\left(u, x_{n}\right)+(1-t)^{2} d^{2}\left(y_{t}, x_{n}\right)+2 t(1-t)\left\langle u x_{n}, y_{t} x_{n}\right\rangle \\
= & t^{2} d^{2}\left(u, x_{n}\right)+(1-t)^{2} d^{2}\left(y_{t}, x_{n}\right)+2 t(1-t)\left\langle u y_{t}, y_{t} x_{n}\right\rangle \\
& +2 t(1-t)\left\langle y_{t} x_{n}, y_{t} x_{n}\right\rangle \\
= & t^{2} d^{2}\left(u, x_{n}\right)+\left((1-t)^{2}+2 t(1-t)\right) d^{2}\left(y_{t}, x_{n}\right)+2 t(1-t)\left\langle u y_{t}, y_{t} x_{n}\right\rangle \\
\leq & t^{2} d^{2}\left(u, x_{n}\right)+\left(1-t^{2}\right)\left(d\left(y_{t}, v_{n, t}\right)+d\left(v_{n, t}, x_{n}\right)\right)^{2}+2 t(1-t)\left\langle u y_{t}, y_{t} x_{n}\right\rangle \\
\leq & t^{2} d^{2}\left(u, x_{n}\right)+\left(1-t^{2}\right) d i s t^{2}\left(y_{t}, T x_{n}\right)+\left(1-t^{2}\right) d^{2}\left(v_{n, t}, x_{n}\right) \\
& +2\left(1-t^{2}\right) d\left(v_{n, t}, x_{n}\right) \operatorname{dist}\left(y_{t}, T x_{n}\right)+2 t(1-t)\left\langle u y_{t}, y_{t} x_{n}\right\rangle \\
\leq & t^{2} d^{2}\left(u, x_{n}\right)+\left(1-t^{2}\right) H^{2}\left(T z_{t}, T x_{n}\right)+\left(1-t^{2}\right) d^{2}\left(v_{n, t}, x_{n}\right) \\
& +2\left(1-t^{2}\right) d\left(v_{n, t}, x_{n}\right) \operatorname{dist}\left(y_{t}, T x_{n}\right)+2 t(1-t)\left\langle u y_{t}, y_{t} x_{n}\right\rangle \\
\leq & t^{2} d^{2}\left(u, x_{n}\right)+\left(1-t^{2}\right) d^{2}\left(z_{t}, x_{n}\right)+\left(1-t^{2}\right) d^{2}\left(v_{n, t}, x_{n}\right) \\
& +2\left(1-t^{2}\right) d\left(v_{n, t}, x_{n}\right) \operatorname{dist}\left(y_{t}, T x_{n}\right)+2 t(1-t)\left\langle u y_{t}, y_{t} x_{n}\right\rangle,
\end{aligned}
$$

which by part $(i i)$ of Lemma 2.2 , for each $t \in(0,1)$ and all $n \in \mathbb{N}$, implies $2 t(1-t)\left\langle u y_{t}, x_{n} y_{t}\right\rangle \leq t^{2} d^{2}\left(u, x_{n}\right)+\left(1-t^{2}\right) d^{2}\left(v_{n, t}, x_{n}\right)+2\left(1-t^{2}\right) d\left(v_{n, t}, x_{n}\right) \operatorname{dist}\left(y_{t}, T x_{n}\right)$.

Hence, for each $t \in(0,1)$, we obtain

$$
\limsup _{n}\left\langle u y_{t}, x_{n} y_{t}\right\rangle \leq \frac{t}{2(1-t)} \limsup _{n} d^{2}\left(u, x_{n}\right) .
$$

On the other hand, since $d\left(y_{t}, p\right)=\operatorname{dist}\left(y_{t}, T p\right) \leq H\left(T z_{t}, T p\right) \leq d\left(z_{t}, p\right)$, sequence $\left\{y_{t}\right\}$ converges to $p$, as $t \rightarrow 0$. So, the continuity of $d$ implies

$$
\left\langle u y_{t}, x_{n} y_{t}\right\rangle \rightarrow\left\langle u p, x_{n} p\right\rangle \text { as } t \rightarrow 0, \text { uniformly respect to } n \text {. }
$$

Therefore, for any number $\varepsilon>0$, there exists $\delta>0$ such that

$$
\left\langle u p, x_{n} p\right\rangle \leq \varepsilon+\left\langle u y_{t}, x_{n} y_{t}\right\rangle,
$$

for all $0<t<\delta$ and all $n \in \mathbb{N}$. This implies that

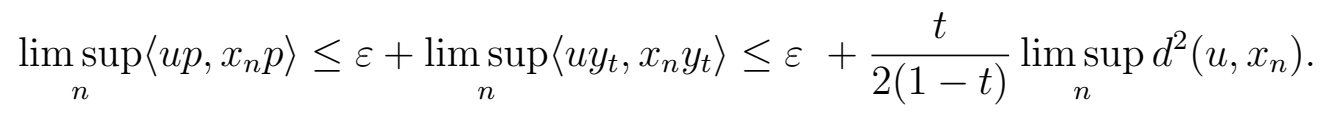

Letting $t \rightarrow 0$, we get

$$
\limsup _{n}\left\langle u p, x_{n} p\right\rangle \leq \varepsilon
$$

Hence, as $\varepsilon \rightarrow 0$, we deduce

$$
\limsup _{n}\left\langle u p, x_{n} p\right\rangle \leq 0 .
$$


Now, we show that $\lim \sup _{n}\left\langle u p, v_{n} p\right\rangle \leq\left\langle u p, x_{n} p\right\rangle$, for all $v_{n} \in T x_{n}$. For all $v_{n} \in T x_{n}$, we have

$$
\begin{aligned}
2\left\langle u p, v_{n} p\right\rangle & =d^{2}(u, p)+d^{2}\left(v_{n}, p\right)-d^{2}\left(u, v_{n}\right) \\
& \leq d^{2}(u, p)+d^{2}\left(x_{n}, p\right)-d^{2}\left(u, x_{n}\right)+d^{2}\left(x_{n}, v_{n}\right)+2 d\left(u, v_{n}\right) d\left(x_{n}, v_{n}\right) \\
& =2\left\langle u p, x_{n} p\right\rangle+d^{2}\left(x_{n}, v_{n}\right)+2 d\left(u, v_{n}\right) d\left(x_{n}, v_{n}\right),
\end{aligned}
$$

which the second inequality is due to

$$
d^{2}\left(u, x_{n}\right) \leq d^{2}\left(u, v_{n}\right)+d^{2}\left(x_{n}, v_{n}\right)+2 d\left(u, v_{n}\right) d\left(x_{n}, v_{n}\right) .
$$

Hence

$$
\limsup _{n}\left\langle u p, v_{n} p\right\rangle \leq \limsup _{n}\left\langle u p, x_{n} p\right\rangle
$$

Lemma 2.6. Suppose $(X, d)$ is a metric space and $C \subset X$. Let $\left\{T_{n}\right\}_{n=1}^{\infty}: C \rightarrow K(C)$ be a sequence of nonexpansive mappings with a common fixed point such that $T_{n}(p)=\{p\}, \quad \forall p \in \bigcap_{n=1}^{\infty} F\left(T_{n}\right)$ and $\left\{x_{n}\right\}$ be a bounded sequence. If $\lim _{n} d\left(x_{n}, u_{n}\right)=0$ for $u_{n} \in T_{n} x_{n}$, then

$$
\limsup _{n}\left\langle u p, u_{n} p\right\rangle \leq \limsup _{n}\left\langle u p, x_{n} p\right\rangle,
$$

where $p \in \bigcap_{n=1}^{\infty} F\left(T_{n}\right)$.

Proof. Let $p \in \bigcap_{n=1}^{\infty} F\left(T_{n}\right)$, we have

$$
\begin{aligned}
2\left\langle u p, u_{n} p\right\rangle & =d^{2}(u, p)+d^{2}\left(u_{n}, p\right)-d^{2}\left(u, u_{n}\right) \\
& \leq d^{2}(u, p)+d^{2}\left(x_{n}, p\right)-d^{2}\left(u, x_{n}\right)+d^{2}\left(x_{n}, u_{n}\right)+2 d\left(u, u_{n}\right) d\left(x_{n}, u_{n}\right) \\
& =2\left\langle u p, x_{n} p\right\rangle+d^{2}\left(x_{n}, u_{n}\right)+2 d\left(u, u_{n}\right) d\left(x_{n}, u_{n}\right),
\end{aligned}
$$

which the second inequality is due to

$$
d^{2}\left(u, x_{n}\right) \leq d^{2}\left(u, u_{n}\right)+d^{2}\left(x_{n}, u_{n}\right)+2 d\left(u, u_{n}\right) d\left(x_{n}, u_{n}\right) .
$$

Hence

$$
\lim \sup _{n}\left\langle u p, u_{n} p\right\rangle \leq \lim \sup _{n}\left\langle u p, x_{n} p\right\rangle .
$$

Finally, the following well-known lemmas are needed to prove the main result.

Lemma 2.7. [1] Let $\left\{s_{n}\right\}$ be a sequence of nonnegative real numbers, $\left\{\alpha_{n}\right\}$ a sequence of real numbers in $[0,1]$ with $\sum_{n=1}^{\infty} \alpha_{n}=\infty,\left\{u_{n}\right\}$ a sequence of nonnegative real numbers with $\sum_{n=1}^{\infty} u_{n}<\infty$, and $\left\{t_{n}\right\}$ a sequence of real numbers with limsup $_{n} t_{n} \leq 0$. Suppose that

$$
s_{n+1} \leq\left(1-\alpha_{n}\right) s_{n}+\alpha_{n} t_{n}+u_{n},
$$

for all $n \in \mathbb{N}$. Then $\lim _{n \rightarrow \infty} s_{n}=0$. 
Lemma 2.8. [16] Let $\left\{s_{n}\right\}$ be a sequence of nonnegative real numbers, $\left\{\alpha_{n}\right\}$ be a sequence of real numbers in $(0,1)$ with $\sum_{n=1}^{\infty} \alpha_{n}=\infty$ and $\left\{t_{n}\right\}$ be a sequence of real numbers. Suppose that

$$
s_{n+1} \leq\left(1-\alpha_{n}\right) s_{n}+\alpha_{n} t_{n} \text { for all } n \geq 1
$$

If limsup $_{k \rightarrow \infty} t_{m_{k}} \leq 0$ for every subsequence $\left\{s_{m_{k}}\right\}$ of $\left\{s_{n}\right\}$ satisfying $\liminf _{k}\left(s_{m_{k}+1}-s_{m_{k}}\right) \geq 0$, then $\lim _{n \rightarrow \infty} s_{n}=0$.

\section{Strong CONVERGEnCE FOR A QUASI-STRONGLY NONEXPANSIVE SEQUENCE}

In this section, we prove the convergence theorem for a quasi-strongly nonexpansive sequence in Hadamard spaces, which extends Theorem 10 in Saejung [14] and improves Theorem 3.7 of [5].

Theorem 3.1. Let $C$ be a closed and convex subset of a complete CAT(0) space $X,\left\{T_{n}\right\}_{n=1}^{\infty}: C \rightarrow K(C)$ be a quasi-strongly nonexpansive sequence and $T: C \longrightarrow K(C)$ be a nonexpansive self-mapping such that

$$
H\left(T_{n}, T\right) \rightarrow 0, \quad \text { uniformly on bounded subsets of } C,
$$

$F(T)=\bigcap_{n=1}^{\infty} F\left(T_{n}\right) \neq \emptyset$ and $T_{n}(p)=\{p\}, \forall p \in F i x(T)$. Suppose that $u, x_{1} \in C$ are arbitrary chosen and $\left\{x_{n}\right\}$ is defined by

$$
x_{n+1}=\alpha_{n} u \oplus\left(1-\alpha_{n}\right) u_{n}, \quad u_{n} \in T_{n} x_{n},
$$

where $\left\{\alpha_{n}\right\}$ is a sequence in $(0,1)$ satisfying

$C 1: \lim _{n \rightarrow \infty} \alpha_{n}=0$,

$C 2: \sum_{n=1}^{\infty} \alpha_{n}=\infty$.

Then $\left\{x_{n}\right\}$ converges to $p \in \bigcap_{n=1}^{\infty} F\left(T_{n}\right)$, which is the nearest point of $F(T)$ to $u$.

Proof. For each $t \in(0,1)$, there exists a unique point $z_{t} \in C$ such that $z_{t}=t u \oplus(1-t) y_{t}$, where $y_{t} \in T z_{t}$. By Lemma 2.4, as $t \rightarrow 0,\left\{z_{t}\right\}$ converges strongly to the unique point $p \in F(T)=\bigcap_{n=1}^{\infty} F\left(T_{n}\right)$, which is the nearest point of $F(T)$ to $u$.

$$
\begin{aligned}
d\left(x_{n+1}, p\right) & \leq \alpha_{n} d(u, p)+\left(1-\alpha_{n}\right) d\left(u_{n}, p\right) \\
& =\alpha_{n} d(u, p)+\left(1-\alpha_{n}\right) \operatorname{dist}\left(u_{n}, T_{n} p\right) \\
& \leq \alpha_{n} d(u, p)+\left(1-\alpha_{n}\right) H\left(T_{n} x_{n}, T_{n} p\right) \\
& \leq \alpha_{n} d(u, p)+\left(1-\alpha_{n}\right) d\left(x_{n}, p\right) \\
& \leq \max \left\{d(u, p), d\left(x_{n}, p\right)\right\} \\
& \leq \ldots \\
& \leq \max \left\{d(u, p), d\left(x_{1}, p\right)\right\}
\end{aligned}
$$


Thus, $\left\{x_{n}\right\}$ and $\left\{u_{n}\right\}$ are bounded.

Moreover, by Lemma 2.3, we have

$$
\begin{aligned}
d^{2}\left(x_{n+1}, p\right) & =d^{2}\left(\alpha_{n} u \oplus\left(1-\alpha_{n}\right) u_{n}, p\right) \\
& \leq \alpha_{n}^{2} d^{2}(u, p)+\left(1-\alpha_{n}\right)^{2} d^{2}\left(u_{n}, p\right)+2 \alpha_{n}\left(1-\alpha_{n}\right)\left\langle u p, u_{n} p\right\rangle \\
& \leq \alpha_{n}^{2} d^{2}(u, p)+\left(1-\alpha_{n}\right)^{2} H^{2}\left(T_{n} x_{n}, T_{n} p\right)+2 \alpha_{n}\left(1-\alpha_{n}\right)\left\langle u p, u_{n} p\right\rangle \\
& \leq\left(1-\alpha_{n}\right) d^{2}\left(x_{n}, p\right)+\alpha_{n}\left(\alpha_{n} d^{2}(u, p)+2\left(1-\alpha_{n}\right)\left\langle u p, u_{n} p\right\rangle\right) .
\end{aligned}
$$

Thus

$$
d^{2}\left(x_{n+1}, p\right) \leq\left(1-\alpha_{n}\right) d^{2}\left(x_{n}, p\right)+\alpha_{n}\left(\alpha_{n} d^{2}(u, p)+2\left(1-\alpha_{n}\right)\left\langle u p, u_{n} p\right\rangle\right)
$$

Hence, by Lemma 2.8 and $C 1$, it suffices to show that $\lim \sup _{k}\left\langle u p, u_{m_{k}} p\right\rangle \leq 0$ for every subsequence $\left(d\left(x_{m_{k}}, p\right)\right)$ of $\left(d\left(x_{n}, p\right)\right)$ satisfying $\liminf _{k}\left(d\left(x_{m_{k}+1}, p\right)-d\left(x_{m_{k}}, p\right)\right) \geq 0$. For this, suppose that $\left(d\left(x_{m_{k}}, p\right)\right)$ is a subsequence of $\left(d\left(x_{n}, p\right)\right)$ such that $\liminf _{k}\left(d\left(x_{m_{k}+1}, p\right)-d\left(x_{m_{k}}, p\right)\right) \geq 0$. Then

$$
\begin{aligned}
0 & \leq \liminf _{k}\left(d\left(x_{m_{k}+1}, p\right)-d\left(x_{m_{k}}, p\right)\right) \\
& \leq \liminf _{k}\left(\alpha_{m_{k}} d(u, p)+\left(1-\alpha_{m_{k}}\right) d\left(u_{m_{k}}, p\right)-d\left(x_{m_{k}}, p\right)\right) \\
& =\liminf _{k}\left(d\left(u_{m_{k}}, p\right)-d\left(x_{m_{k}}, p\right)\right)+\limsup _{k}\left(\alpha_{m_{k}}\left(d(u, p)-d\left(u_{m_{k}}, p\right)\right)\right) \\
& =\liminf _{k}\left(d\left(u_{m_{k}}, p\right)-d\left(x_{m_{k}}, p\right)\right) \\
& =\liminf _{k}\left(\operatorname{dist}\left(u_{m_{k}}, T_{m_{k}} p\right)-d\left(x_{m_{k}}, p\right)\right) \\
& \leq \liminf _{k}\left(H\left(T_{m_{k}} x_{m_{k}}, T_{m_{k}} p\right)-d\left(x_{m_{k}}, p\right)\right) \\
& \leq \limsup _{k}\left(H\left(T_{m_{k}} x_{m_{k}}, T_{m_{k}} p\right)-d\left(x_{m_{k}}, p\right)\right) \\
& \leq \limsup _{k}\left(d\left(x_{m_{k}}, p\right)-d\left(x_{m_{k}}, p\right)\right)=0
\end{aligned}
$$

hence

$$
\lim _{k}\left(H\left(T_{m_{k}} x_{m_{k}}, T_{m_{k}} p\right)-d\left(x_{m_{k}}, p\right)\right)=0 .
$$

Since $\left\{x_{m_{k}}\right\}$ is bounded and $\left\{T_{n}\right\}$ is quasi-strongly nonexpansive sequence, we get

$$
\lim _{k} d\left(x_{m_{k}}, u_{m_{k}}\right)=0, \quad \text { for all } \quad u_{m_{k}} \in T_{m_{k}} x_{m_{k}} .
$$

On the other hand, for every $v_{m_{k}} \in T x_{m_{k}}$ there exists $u_{m_{k}} \in T_{m_{k}} x_{m_{k}}$ such that $d\left(v_{m_{k}}, u_{m_{k}}\right)=\operatorname{dist}\left(v_{m_{k}}, T_{m_{k}} x_{m_{k}}\right)$. Thus for every $v_{m_{k}} \in T x_{m_{k}}$ there exists $u_{m_{k}} \in T_{m_{k}} x_{m_{k}}$ such that

$$
\begin{aligned}
d\left(x_{m_{k}}, v_{m_{k}}\right) & \leq d\left(x_{m_{k}}, u_{m_{k}}\right)+d\left(u_{m_{k}}, v_{m_{k}}\right) \\
& =d\left(x_{m_{k}}, u_{m_{k}}\right)+\operatorname{dist}\left(v_{m_{k}}, T_{m_{k}} x_{m_{k}}\right) \\
& \leq d\left(x_{m_{k}}, u_{m_{k}}\right)+H\left(T x_{m_{k}}, T_{m_{k}} x_{m_{k}}\right) .
\end{aligned}
$$

Therefore (3.1) and (3.3) imply $\lim _{k \rightarrow \infty} d\left(x_{m_{k}}, v_{m_{k}}\right)=0$, for all $v_{m_{k}} \in T x_{m_{k}}$. Thus, by Lemma 2.5, $\lim \sup _{k}\left\langle u p, x_{m_{k}} p\right\rangle \leq 0$. Hence, by (3.3) and Lemma 2.6, 
we obtain

$$
\limsup _{k}\left\langle u p, u_{m_{k}} p\right\rangle \leq 0, \quad \text { for all } \quad u_{m_{k}} \in T_{m_{k}} x_{m_{k}} .
$$

Hence Lemma 2.8, $C 1, C 2$, (3.4) and (3.2) imply $\lim _{n \rightarrow \infty} d\left(x_{n}, p\right)=0$. That is the desired result.

\section{Strong CONVERGEnCE FOR A FAmily of NONEXPANSIVE MAPPINGS}

In the following theorem, we prove the result of Theorem 3.7 of [5] without using Banach limit. Since the following proof does not use Banach limits, that is a consequence of Zorn's lemma, it seems that it is more constructive and useful from practical point of view.

Theorem 4.1. Let $C$ be a closed and convex subset of complete $C A T(0)$ space $X$, $\left\{T_{n}\right\}_{n=1}^{\infty}: C \rightarrow K(C)$ be a family of nonexpansive mappings and $T: \quad C \longrightarrow K(C)$ be a nonexpansive self-mapping such that $F(T)=\bigcap_{n=1}^{\infty} F\left(T_{n}\right) \neq \emptyset, T_{n}(p)=T(p)=\{p\}, \forall p \in F i x(T)$, and for all bounded sequence $\left\{x_{n}\right\} \subset C$, we have $\lim _{n} d\left(v_{n}, u_{n}\right)=0$ for all $u_{n} \in T_{n} x_{n}$ and $v_{n} \in T x_{n}$. Suppose that $u, x_{1} \in C$ are arbitrary chosen and $\left\{x_{n}\right\}$ is defined by

$$
x_{n+1}=\alpha_{n} u \oplus\left(1-\alpha_{n}\right) u_{n}, \quad u_{n} \in T_{n} x_{n},
$$

where $\left\{\alpha_{n}\right\}$ is a sequence in $(0,1)$ satisfying

$C 1: \lim _{n \rightarrow \infty} \alpha_{n}=0$,

$C 2: \sum_{n=1}^{\infty} \alpha_{n}=\infty$,

$C 3: \sum_{n=1}^{\infty}\left|\alpha_{n}-\alpha_{n+1}\right|<\infty$ or $\lim _{n} \frac{\alpha_{n}}{\alpha_{n+1}}=1$.

If $d\left(u_{n+1}, u_{n}\right) \leq d\left(x_{n+1}, x_{n}\right)+e_{n}$ with $\sum_{n=1}^{\infty} e_{n}<\infty$, then $\left\{x_{n}\right\}$ converges to $p \in \bigcap_{n=1}^{\infty} F\left(T_{n}\right)$, which is the nearest point of $F(T)$ to $u$.

Proof. We can easily obtain that $\left\{x_{n}\right\}$ and $\left\{u_{n}\right\}$ are bounded. From the definition of $x_{n}$, we see that

$$
\begin{aligned}
d\left(x_{n+1}, x_{n}\right)= & d\left(\alpha_{n} u \oplus\left(1-\alpha_{n}\right) u_{n}, \alpha_{n-1} u \oplus\left(1-\alpha_{n-1}\right) u_{n-1}\right) \\
\leq & d\left(\alpha_{n} u \oplus\left(1-\alpha_{n}\right) u_{n}, \alpha_{n} u \oplus\left(1-\alpha_{n}\right) u_{n-1}\right) \\
& +d\left(\alpha_{n} u \oplus\left(1-\alpha_{n}\right) u_{n-1}, \alpha_{n-1} u \oplus\left(1-\alpha_{n-1}\right) u_{n-1}\right) \\
\leq & \left(1-\alpha_{n}\right) d\left(u_{n}, u_{n-1}\right)+\left|\alpha_{n}-\alpha_{n-1}\right| d\left(u, u_{n-1}\right) \\
\leq & \left(1-\alpha_{n}\right) d\left(x_{n}, x_{n-1}\right)+e_{n-1}+\left|\alpha_{n}-\alpha_{n-1}\right| d\left(u, u_{n-1}\right) .
\end{aligned}
$$

Thus, by assumptions, Lemma 2.7 implies $\lim _{n} d\left(x_{n+1}, x_{n}\right)=0$. On the other hand, $d\left(x_{n}, u_{n}\right) \leq d\left(x_{n}, x_{n+1}\right)+d\left(x_{n+1}, u_{n}\right)=d\left(x_{n}, x_{n+1}\right)+\alpha_{n} d\left(u, u_{n}\right)$ which by $C 1$ implies

$$
d\left(x_{n}, u_{n}\right) \rightarrow 0
$$

This together with the assumptions implies that for all $v_{n} \in T x_{n}$

$$
d\left(x_{n}, v_{n}\right) \leq d\left(x_{n}, u_{n}\right)+d\left(u_{n}, v_{n}\right) \rightarrow 0 .
$$

Thus, by Lemma 2.5, $\lim \sup _{n}\left\langle u p, x_{n} p\right\rangle \leq 0$. Hence, by (4.1) and Lemma 2.6, we have

$$
\limsup _{n}\left\langle u p, u_{n} p\right\rangle \leq 0
$$


By Lemma 2.3, we have

$$
\begin{aligned}
d^{2}\left(x_{n+1}, p\right) & =d^{2}\left(\alpha_{n} u \oplus\left(1-\alpha_{n}\right) u_{n}, p\right) \\
& \leq \alpha_{n}^{2} d^{2}(u, p)+\left(1-\alpha_{n}\right)^{2} d^{2}\left(u_{n}, p\right)+2 \alpha_{n}\left(1-\alpha_{n}\right)\left\langle u p, u_{n} p\right\rangle \\
& \leq \alpha_{n}^{2} d^{2}(u, p)+\left(1-\alpha_{n}\right)^{2} \operatorname{dist}^{2}\left(u_{n}, T_{n} p\right)+2 \alpha_{n}\left(1-\alpha_{n}\right)\left\langle u p, u_{n} p\right\rangle \\
& \leq \alpha_{n}^{2} d^{2}(u, p)+\left(1-\alpha_{n}\right)^{2} H^{2}\left(T_{n} x_{n}, T_{n} p\right)+2 \alpha_{n}\left(1-\alpha_{n}\right)\left\langle u p, u_{n} p\right\rangle \\
& \leq\left(1-\alpha_{n}\right) d^{2}\left(x_{n}, p\right)+\alpha_{n}\left(\alpha_{n} d^{2}(u, p)+2\left(1-\alpha_{n}\right)\left\langle u p, u_{n} p\right\rangle\right),
\end{aligned}
$$

which by (4.2), $C 1, C 2$ and Lemma 2.7 implies $\lim _{n} d^{2}\left(x_{n+1}, p\right)=0$.

Hence, $\left\{x_{n}\right\}$ converges to $p \in F(T)=\bigcap_{n=1}^{\infty} F\left(T_{n}\right)$, which is the nearest point of $F(T)$ to $u$.

Remark 4.2. In Theorems 3.1 and 4.1, it suffices to assume that $C$ is a complete $\mathrm{CAT}(0)$ space and it is not necessary that $X$ is a complete $\mathrm{CAT}(0)$ space.

Acknowledgement. The authors are grateful to the referee for his(her) careful reading and valuable comments and suggestions.

\section{REFERENCES}

1. K. Aoyama, Y. Kimura, W. Takahashi and M. Toyoda, Approximation of common fixed points of a countable family of nonexpansive mappings in a Banach space, Nonlinear Anal. 67 (2007), 2350-2360.

2. M. Bridson and A. Haefliger, Metric Spaces of Non-Positive Curvature, Fundamental Principles of Mathematical Sciences, Springer, Berlin, 1999.

3. D. Burago, Y. Burago, and S. Ivanov, A Course in Metric Geometry, Graduate Studies in Math. 33, Amer. Math. Soc. Providence, RI, 2001.

4. C.E. Chidume and C.O. Chidume, Iterative approximation of fixed points of nonexpansive mappings, J. Math. Anal. Appl. 318 (2006), 288-295.

5. S. Dhompongsa, A. Kaewkhao and B. Panyanak, On Kirks strong convergence theorem for multivalued nonexpansive mappings on CAT(0) spaces, Nonlinear Anal. 75 (2012), 459-468.

6. S. Dhompongsa and B. Panyanak, On $\Delta$-convergence theorems in CAT(0) spaces, Comput. Math. Appl. 56 (2008), no. 10, 2572-2579.

7. M. Gromov and S.M. Bates, Metric Structures for Riemannian and Non-Riemannian Spaces, with appendices by M. Katz, P. Pansu and S. Semmes, ed. by J. Lafontaine and P. Pansu, Progr. Math. 152, BirkhNauser, Boston 1999.

8. B. Halpern, Fixed points of nonexpanding maps, Bull. Amer. Math. Soc. 73 (1967), 957-961.

9. J. Jöst, Nonpositive Curvature: Geometric and Analytic Aspects, Lectures Math. ETH Zurich, Birkhäuser, Basel 1997.

10. W.A. Kirk, Geodesic geometry and fixed point theory, Paper presented at the Seminar of Mathematical Analysis, University of Sevilla Secretry, sevilla, spain, 64 (2003), 195-225.

11. W.A. Kirk, Geodesic geometry and fixed point theory II. Paper presented at the International Conference on Fixed Point Theory and Applications, Yokohama Publ. (2004), 113-142.

12. P.L. Lions, Approximation de points fixes de contractions, C.R. Acad. Sci. Paris Ser. A-B, 284 (1977), no. 21, A1357-A1359.

13. S. Nadler, Multivalued contraction mappings, Pacific J. Math. 30 (1969), 475-488.

14. S. Saejung, Halpern's iteration in Banach spaces, Nonlinear Anal. 73 (2010), 3431-3439.

15. S. Saejung, Halpern's iteration in CAT(0) spaces, Fixed Point Theory Appl. Art. ID. 471781, (2010), 13 pp. 
16. S. Saejung and P. Yotkaew, Approximation of zeros of inverse strongly monotone operators in Banach spaces, Nonlinear Anal. 75 (2012), 742-750.

17. T. Suzuki, A sufficient and necessary condition for Halpern-type strong convergence to the fixed point of nonexpansive mapping, Proc. Amer. Math. Soc. 135 (2007), 99-106.

18. R. Wittmann, Approximation of fixed points of nonexpansive mappings, Arch. Math. 58 (1992), 486-491.

Department of Mathematics, University of Zanjan, P.O. Box 45195-313, ZanJAN, IRAN.

E-mail address: hkhatibzadeh@znu.ac.ir; sranjbar@znu.ac.ir 